\title{
A Conserved Oomycete CRN Effector Targets Tomato TCP14-2 to Enhance Virulence
}

\author{
Remco Stam, ${ }^{1,2}$ Graham B. Motion, ${ }^{1,2}$ Victor Martinez-Heredia, ${ }^{1}$ Petra C. Boevink, ${ }^{2}$ and Edgar Huitemaa ${ }^{1, \dagger}$ \\ ${ }^{1}$ Division of Plant Sciences, University of Dundee at the James Hutton Institute, Invergowrie, Dundee DD2 5DA, \\ United Kingdom \\ ${ }^{2}$ Cell and Molecular Sciences, James Hutton Institute, Invergowrie, Dundee DD2 5DA, United Kingdom
}

Accepted 27 November 2020.

\begin{abstract}
Phytophthora spp. secrete vast arrays of effector molecules during infection to aid in host colonization. The crinkling and necrosis (CRN) protein family forms an extensive repertoire of candidate effectors that accumulate in the host nucleus to perturb processes required for immunity. Here, we show that CRN12_997 from Phytophthora capsici binds a TCP transcription factor, SITCP14-2, to inhibit its immunity-associated activity against Phytophthora spp. Coimmunoprecipitation and bimolecular fluorescence complementation studies confirm a specific CRN12_997-SITCP14-2 interaction in vivo. Coexpression of CRN12_997 specifically counteracts the TCP14enhanced immunity phenotype, suggesting that CRN mediated perturbation of SITCP14-2 function. We show that SITCP14-2 associates with nuclear chromatin and that CRN12_997 diminishes SITCP14-2 DNA binding. Collectively, our data support a model in which SITCP14-2 associates with chromatin to enhance immunity. The interaction between CRN12_997 and SITCP14-2 reduces DNA binding of the immune regulator. We propose that the modulation of SITCP14-2 chromatin affinity, caused by CRN12-997, enhances susceptibility to $P$. capsici.
\end{abstract}

Keywords: oomycete effectors, oomycete-plant interactions, Phytophthora diseases

Oomycete pathogens rank among the greatest threats to plants, animals, and ecosystems (Fisher et al. 2012). Within the Oomycetes lineage, members of the Phytophthora genus form a devastating group of pathogens that affect nearly all dicot crops. For example, under conducive environmental conditions

Current address for R. Stam: Chair of Phytopathology, Technical University Munich.

${ }^{\dagger}$ Corresponding author: E. Huitema; e.huitema@ dundee.ac.uk

Funding: This research was funded by the Biotechnology and Biological Sciences Research Council (BB/I00386X/1), the FP7 Ideas: European Research Council (grant number 310901), and the Royal Society of Edinburgh (RSE Personal Research Fellowship). P. C. Boevink is funded, in part, by the Scottish Government Rural and Environment Science and Analytical Service Department.

*The $\boldsymbol{e}$-Xtra logo stands for "electronic extra" and indicates that a supplementary file and supplementary figures are published online.

The author(s) declare no conflict of interest.

Copyright $\odot 2021$ The Author(s). This is an open access article distributed under the CC BY-NC-ND 4.0 International license. and in the absence of (chemical) control measures, Phytophthora infestans and $P$. sojae can decimate potato and soybean crops in a matter of days (Fry 2008; Tyler 2007), severely reducing yields. Although some Phytophthora spp. infect only a few crops, others such as $P$. cinnamomi, $P$. nicotianae, and $P$. capsici have broad host ranges, infecting crops from diverse plant families. As these pathogens continue to threaten food production, there is significant interest in understanding the basis of Phytophthora virulence, host range, and, by extension, resistance.

Given that plants associate with a wide range of organisms, they require a finely tuned host immune signaling network. Therefore, it is not surprising that efforts to map the Arabidopsis immune signaling network have identified a vast and complex set of interconnected signaling cascades that regulate immunity. The existence of intricate pathways explains how plants mount the appropriate immune response against diverse microbes (Arabidopsis Interactome Mapping Consortium 2011; Carella et al. 2018; Gassmann and Bhattacharjee 2012; Spoel and Dong 2012).

Pathogens deploy diverse arsenals of secreted proteins (effectors) during infection. Although some accumulate and function in the host apoplast, others translocate inside host cells, where they travel to distinct subcellular compartments and target resident host proteins. Effector proteins then modify target function, leading to perturbation of cellular processes that drive immune responses. Effector-target interactions thus form the principal means by which (cytoplasmic) effectors trigger susceptibility to pathogens (effector-triggered susceptibility [ETS]) (Hogenhout et al. 2009; Jones and Dangl 2006). To understand pathogen virulence strategies or, more specifically, the roles of effectors in host invasion and colonization, we must identify their host targets.

We now know that several bacterial effectors act as nucleomodulins (Bierne and Cossart 2012). These effectors target host DNA or regulatory factors to interfere with the plants' defense mechanisms (Ma et al. 2011). Systems-level analyses of effector-target interactions and the nuclear immune signaling network topology provide additional insights into how diverse pathogens target key immune regulators (hubs) to achieve virulence (Pritchard and Birch 2011). A matrix twohybrid screen using effector proteins from the oomycete $\mathrm{Hya}$ loperonospora arabidopsidis and the bacterial pathogen Pseudomonas syringae against a large protein set from Arabidopsis thaliana demonstrated that effector arsenals encoded by diverse pathogens share host targets. Common host targets often are important hubs in the Arabidopsis immune regulatory network (Mukhtar et al. 2011). One such example is the Arabidopsis transcription factor TCP14 (AtTCP14). AtTCP14 is a major hub that regulates growth 
and immune responses and is targeted by effectors from $H$. arabidopsidis and P. syringae (Mukhtar et al. 2011) as well as the fungal pathogen Golovinomyces orontii (Weßling et al. 2014). TCP proteins form a large family of transcription factors with a DNA-binding basic helix-loop-helix domain, dubbed the TCP domain (Kosugi and Ohashi 1997). AtTCP14 plays various roles in plant growth and development (Cubas et al. 1999; Kieffer et al. 2011; Steiner et al. 2012). This transcription factor was found to regulate defense gene expression in antagonism to SRFR1, a negative regulator of effector-triggered immunity (Kim et al. 2014). AtTCP14 is a negative regulator of jasmonic acid (JA) regulation and, in this capacity, it is targeted by the $P$. syringae effector HopBB1. This effector directly binds to AtTCP14 and targets it for $\mathrm{SCF}^{\mathrm{CO} 1}{ }_{\text {-dependent degradation, }}$ thereby downregulating JA-associated defense responses (Yang et al. 2017). In addition to AtTCP14, other family members appear to act as regulators of immunity. The characterization of SAP11, an effector from Aster yellows phytoplasma, strain Witches' Broom (AY-WB), revealed that it destabilizes CINCINNATA (CIN)-related TCPs. TCP depletion, in turn, leads to a compromised JA response and enhanced fecundity of its insect vector Macrosteles quadrilineatus. Suppression of immunity against the vector thereby facilitates the transmission and spread of AY-WB (Sugio et al. 2011).

Phytophthora genomes encode at least two major classes of intracellular effectors that contribute to virulence. RXLR effectors are named after their N-terminal Arg-X-Leu-Arg motif, whereas crinkling and necrosis (CRN) proteins all carry an LFLAK motif (Leu-Phe-Leu-Ala-Lys) in their $\mathrm{N}$ terminus (Amaro et al. 2017; Schornack et al. 2009, 2010; Stam et al. 2013b). Members of both effector families are modular proteins with conserved $\mathrm{N}$ termini thought to specify translocation, whereas C-terminal domains carry effector activities. Intriguingly, $\mathrm{CRN}$ proteins are more widespread in the oomycetes than the RXLR effector class. CRN-coding genes are present in the genome of all plant-pathogenic oomycetes sequenced to date, including Phytophthora spp., Hyaloperonospora spp., and basal oomycete species such as Aphanomyces spp. In contrast, genes encoding RXLR effectors only appear to be present in members of the Peronosporales lineage (Baxter et al. 2010; Gaulin et al. 2008; Haas et al. 2009; Lamour et al. 2012; Lévesque et al. 2010; Links et al. 2011; Tyler et al. 2006). CRN $\mathrm{N}$-terminal regions, along with some of their C-terminal counterparts, are highly conserved among plant-pathogenic oomycetes, suggesting fundamental roles in oomycete biology or parasitism (Stam et al. 2013b). However, we still know very little about their contribution to virulence. Localization of CRN domains in plants revealed that a diverse array of Cterminal effector domains from a wide range of oomycetes accumulate in nuclei. Some CRN domains cause cell death and chlorosis phenotypes in plants, suggesting perturbation of cellular processes by the effector activities carried by CRN C termini (Amaro et al. 2018; Liu et al. 2011; Stam et al. 2013 a,b). Interestingly, whereas CRNs were identified due to their cell-death-inducing capacity, several examples of cell death suppression by CRNs exist (Maximo et al. 2019).

In $H$. arabidopsidis, effectors with a joined RXLR and CRN domain appear to target Arabidopsis TCPs (Mukhtar et al. 2011). Molecular analysis revealed that, in the case of the Phytophthora infestans CRN8 effector domain, it needs to accumulate in the host nucleus to induce cell death. Additionally, PiCRN8 has kinase activity in planta, suggesting that it may be this that aids the infection process (van Damme et al. 2012). More recently, Ramirez-Garcés et al. (2016) showed that AeCRN13 directly binds to DNA and triggers a plant DNA damage response, ultimately leading to cell death after overexpression of the protein in planta. Similarly, Song et al. (2015) found that PsCRN108 contain a DNA-binding HhHmotif through which it targets sites associated with heat shock protein promotors (HSPs) and interferes with HSP-associated defense responses. Intriguingly, some CRN effector domains can form hetero dimers inside hosts. These observations raise the possibility that CRN effectors act combinatorially, vastly expanding the range of possible mechanistic routes to immune suppression (Li et al. 2016). These studies exemplify the diversity and flexibility found within the CRN protein family and raise the possibility that other, as-yet-unknown mechanisms of action exist.

Here, we show that Phytophthora capsici seems to employ yet another nuclear strategy. CRN12_997 interacts with the tomato transcription factor SITCP14-2 in planta. We show that the presence of CRN12_997 reduces the level of SITCP14-2 bound to chromatin. We suggest that CRN12_997 binds a complex containing SITCP14-2 which leads to enhanced susceptibility or lowered resistance in the host.

\section{RESULTS}

\section{TCP14 and CRN orthologs are present in tomato and $P$. capsici.}

We previously reported that the CRN effector repertoire is widespread among plant-pathogenic oomycetes and that a subset of these CRNs, containing specific effector domains, is present in most sequenced species (Stam et al. 2013b). The DXX C-terminal domain is among the most conserved domains, and is often flanked by other domains. In $H$. arabidopsidis, three DHB-DXX-DHA domain-containing effectors have been identified, all of which putatively interact with the transcription factor AtTCP14 in yeast (Mukhtar et al. 2011). Thus, we asked whether CRN-TCP14 interactions could occur within the $P$. capsici-tomato pathosystem. Comparisons between $H$. arabidopsidis and $P$. capsici candidate effectors helped identify two CRN candidates with DHB-DXX-DHA domain combinations (Supplementary Fig. S1A and B). Comparisons between PcCRN12_997 and PcCRN125_11 and their possible $H$. arabidopsidis counterparts (HaRXLCRN4, -15, and -17), revealed at least $41 \%$ sequence identity in pairwise alignments between C-terminal domains (Supplementary Fig. S1C). To assess relationships between CRN proteins with DHB-DXX-DXA domain configurations in different species, we made a phylogenetic reconstruction of the C-terminal domains using CRN1_719, which has a different domain structure, as the outgroup. These analyses show that CRN coding genes group together in species-specific clusters (Supplementary Fig. S1B), suggesting that C-terminal DHB-DXX-DXA domain architecture was present before speciation and subsequent gene duplications might have occurred after speciation. Both $P$. capsici CRN coding genes are expressed during infection (Supplementary Fig. S1D), suggesting that they encode functional proteins. Additionally, we subjected CRN12_997 and CRN125_11 to PFAM domain searches. These searches revealed no significant hits for known DNA-binding domains, unlike for previously studied CRNs in $P$. sojae (Song et al. 2015) or Aphanomyces euteiches (Ramirez-Garcés et al. 2016). If CRN-target interactions are both ancestral and preserved, P. capsici CRN12_997 or CRN125_11 may directly bind AtTCP14 orthologs during infection.

BLAST analyses identified two putative tomato orthologs of AtTCP14, which we named SITCP14-1 (Solyc06g070900.2.1) and SITCP14-2 (Solyc03g116320.2.1). Both share high sequence similarity with AtTCP14, though they are more similar to each other than to AtTCP14 (Supplementary Fig. S2A). Both tomato TCP proteins contain the highly conserved helix-loop- 
helix domain, including the conserved cysteine at the start of the first helix (Viola et al. 2013) (Supplementary Fig. S2A). To learn more about SITCP14 gene expression, we examined expression data from a $P$. capsici infection time course on tomato (Jupe et al. 2013). These data show that both SITCP14-1 and SITCP14-2 are initially expressed in tomato upon infection, followed by downregulation in the ensuing time points (Supplementary Fig. S2B). SITCP14-1 expression increases again after $24 \mathrm{~h}$, whereas SITCP14-2 transcript levels remain reduced (Supplementary Fig. S2B).

\section{SITCP14-2 contributes to immunity against $P$. capsici.}

Pathogen effectors are factors that modulate host cell signaling and impair immunity. Because AtTCP14 emerged as a contributor to immunity in Arabidopsis (Mukhtar et al. 2011), we asked whether SITCP14-1 and SITCP14-2 functions are analogous in solanaceous plants. For this purpose, we ectopically expressed SITCP14 proteins in Nicotiana benthamiana as well as an empty vector (EV) (enhanced green fluorescent protein [EGFP] only) and infected infiltrated leaf panels with $P$. capsici zoospores as described previously (Stam et al. 2013a). Ectopic expression of SITCP14-2 impaired P. capsici infection, evidenced by the reduction of lesion size when compared with EV controls ( $t$ test, $P<0.01$ ) (Fig. 1A). This phenotype was specific to SITCP14-2 because $P$. capsici colonized panels expressing S1-TCP14-1 at a similar rate when compared with the EV control (Fig. 1A). Importantly, in an independent experiment, ectopic expression of a closely related $N$. benthamiana homolog of SITCP14-2 (NbTCP14-2) also reduced $P$. capsici growth (Supplementary Fig. S3A and B), suggesting that SITCP14-2 is functionally equivalent to NbTCP14. We could not attribute the differences in
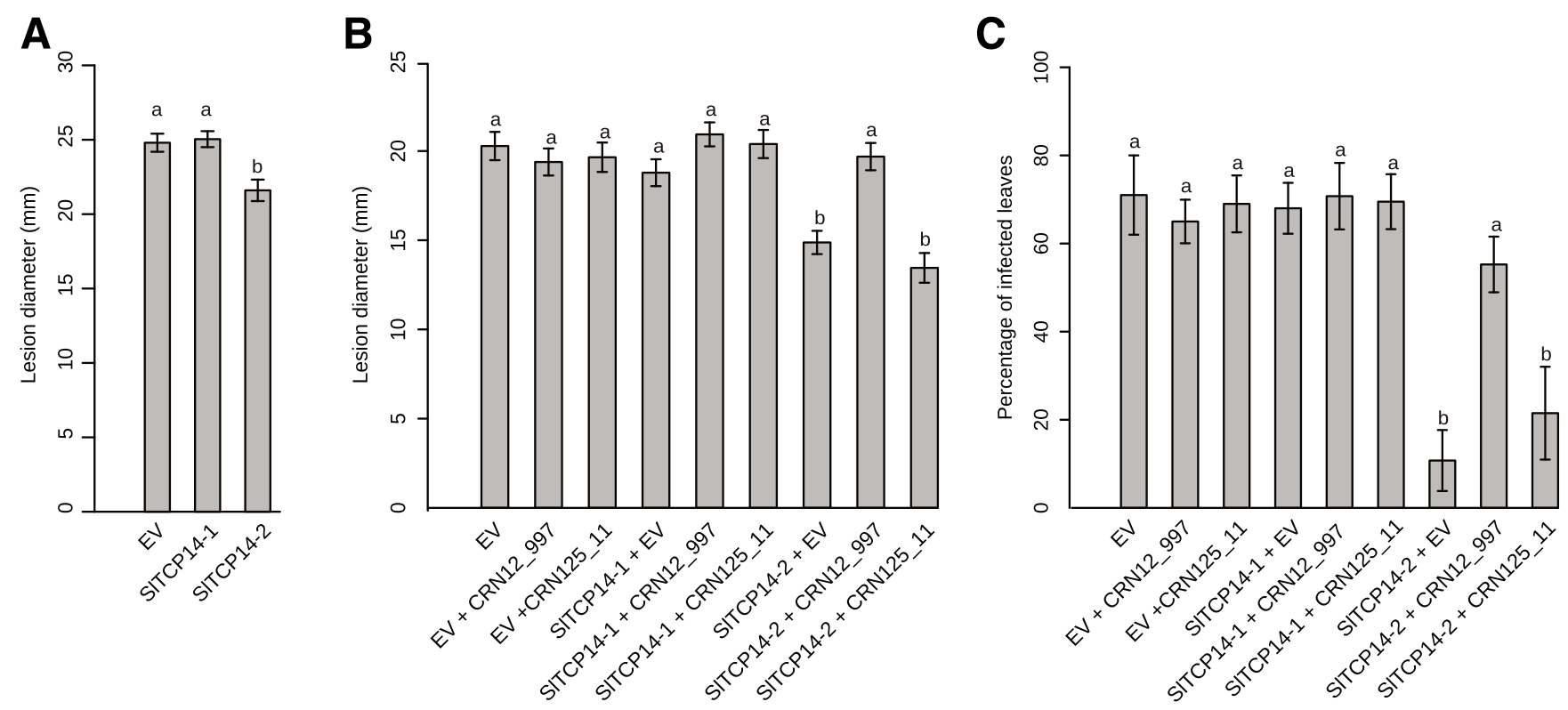

$D_{\text {EV }}$

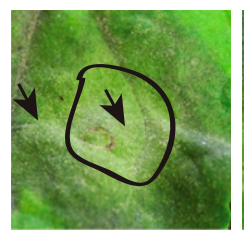

E

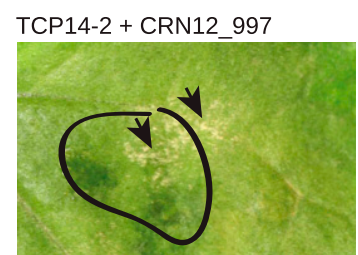

SITCP14-1

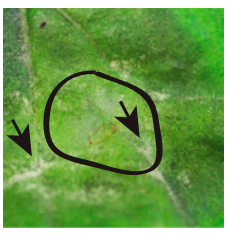

TCP14-2 + CRN125_11

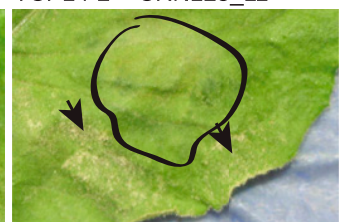

SITCP14-2

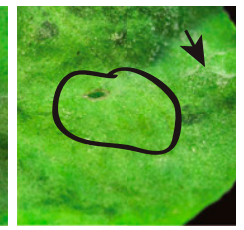

$\mathbf{F}$

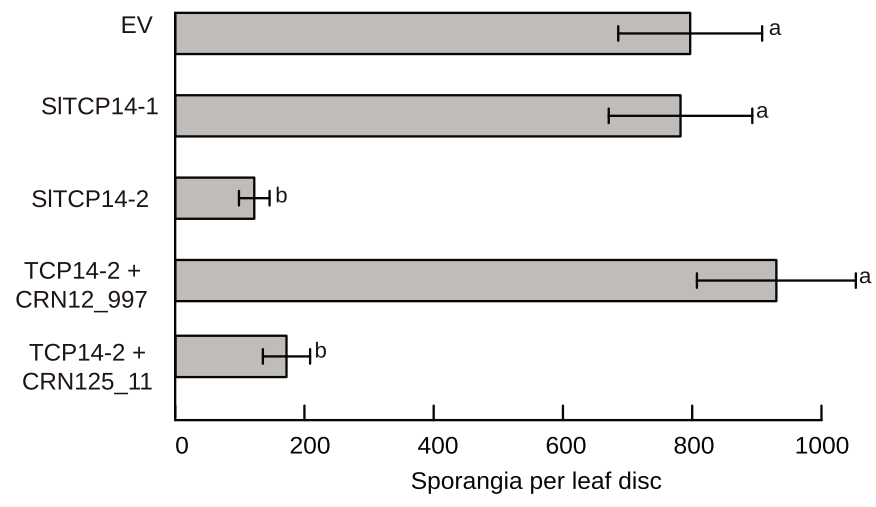

Fig. 1. Overexpression of SITCP14-2 enhances resistance against Phytophthora capsici, and coexpression of crinkling and necrosis (CRN)12_997 is able to overcome this resistance. A, Overexpression of green fluorescent protein (GFP)-tagged SITCP14-1, SITCP14-2, and free enhanced GFP (EGFP) was followed by $P$. capsici zoospore inoculation. Lesion size was measured at 3 days postinfection (dpi); $n=25$. B, CRN12_997 and CRN125_11 were expressed in combination with empty vector (EV) (EGFP), SITCP14-1, and SITCP14-2 as denoted and the impact on infection was measured as described in A; $n=25$. C, Nicotiana benthamiana leaves expressing combinations as shown in B were inoculated with low-density $P$. capsici spore suspensions. Inoculated leaves were scored at $1 \mathrm{dpi}$ and the percentage of infected leaves was calculated as (lesions/inoculations) $\times 100 ; n>40$. D, Leaf panels expressing SITCP14-1, SITCP14-2, and EV (EGFP) were inoculated with P. capsici zoospores. Sporangia (arrowheads) are visible as white structures against macerated plant tissue and mycelium inside and outside the infiltrated region (black line) of the leaf for both our EV control and SITCP14-1. No sporangia can be observed within infiltrated sites expressing SITCP14-2. Pictures were taken 3 days after inoculation. E, Occurrence of sporulation on panels expressing SITCP14-2-CRN combinations. Coinfiltration with CRN12_997 but not with CRN125_11 restored sporulation in the presence of SITCP14-2. Sporangia (arrowheads) can be observed at 3 dpi within the infiltration site (black line). F, The average number of sporangia per leaf disc inside the infiltration site. The effect of CRN12_997 on increasing sporulation rates in the presence of SITCP14-2 was significant. Leaf disks were collected 2 dpi and sporangia were resuspended in distilled water prior to counting in a counting chamber under a light microscope. For each treatment, $n>10$. Error bars indicate standard errors. Bars marked with different lowercase letters are significantly different from each other (multiple $t$ tests, $P<0.01$ ). 
susceptibility to the levels of overexpression. Infiltration and ectopic expression of all constructs led to the production of detectable protein in unchallenged $N$. benthamiana leaves (Supplementary Fig. S3C).

\section{CRN12_997 counteracts SITCP14-2 mediated immunity against $P$. capsici.}

Given that SITCP14-2 overexpression enhances immunity to P. capsici, we hypothesized that endogenous CRN12_997 usually is sufficient to suppress immunity but the high levels of SITCP14-2 generated by ectopic expression renders endogenous CRN12_997 levels inadequate to enhance virulence. If true, adding ectopic expression of CRN12_997 should boost $P$. capsici growth in the presence of overexpressed SITCP14-2. We coinfiltrated both SITCP14-1 and SITCP14-2 with CRN12_997, CRN125_11, or EV, followed by $P$. capsici infection assays (Fig. 1B). These experiments showed that CRN12_997 cooverexpression reconstitutes growth to levels seen in EV controls (Fig. 1B). We only observed the restoration of growth when CRN12_997 was coexpressed with SITCP14-2. CRN125_11 failed to enhance growth in the presence of elevated SITCP14-2 levels (Fig. 1B). Experiments in which NbTCP14 was coexpressed with CRN12_997 and CRN125_11 showed similar results. Only CRN12_997 overexpression could counteract the immunity phenotype that is induced by elevated NbTCP14 levels (Supplementary Fig. S3B). In addition to lesion size as a proxy for immunity, we also assessed the effect of SITCP14-CRN coexpression on infection frequency (using lower amounts of $P$. capsici zoospores per inoculation). These experiments revealed that SITCP14-2 overexpression significantly reduces infection frequencies, ranging from 68 to $71 \%$ in the controls compared with $11 \%$ in SITCP14-2-expressing leaves (Fig. 1C). Coexpression with CRN12_997 but not CRN125_11 restored the infection rates to levels seen in the controls (55\%) (Fig. 1C). Finally, we observed that leaf panels expressing SITCP14-2 exhibit a delay in the onset of sporulation (Fig. 1D). We recorded the formation of sporangia 3 days postinfection (dpi) exclusively outside the infiltration area (Fig. 1D). This observation was specific to TCP14 activity because sporulation appeared unaffected on leaf panels infiltrated with EV control, SITCP14-1, or the CRN12_997-SITCP14-2 combination. In those cases, we observed sporulation in the infiltrated regions (Fig. 1D and E). To confirm our macroscopic observations, we repeated these experiments to collect discs from our infiltrated and $P$. capsici-infected leaf panels and quantify sporulation levels (Fig. 1F). Spore counts for each treatment revealed that only expression of SITCP14-2 had a significant effect on sporulation (Fig. 1F). Coexpression of CRN12_997 but not CRN125_11 restored sporulation to normal levels (Fig. 1F). Our results suggest that SITCP14-2 but not SITCP14-1 overexpression elevates immunity against $P$. capsici, a phenotype that can be countered by coexpression of CRN12_997 but not CRN125_11.

\section{Coimmunoprecipitation confirms the interaction of CRN12_997 and SITCP14-2 in vivo.}

Given the observation that SITCP14-2 overexpression reduces $P$. capsici infection and that CRN12_997 expression counters this phenotype, we tested whether the proteins could interact in vivo. We immunoprecipitated FLAG-tagged CRN and EGFP-TCP fusion proteins to assess protein-protein interactions in vivo. We coexpressed SITCP14-2 with either CRN12_997, CRN125_11, or unrelated CRN1_719 in $N$. benthamiana. Complexes were purified from total leaf extracts using GFP-trap magnetic beads. Immunoprecipitation of both GFP-tagged TCPs in the presence of FLAG-tagged CRN proteins only resulted in coimmunoprecipitation of
CRN12_997 with SITCP14-2 (Fig. 2A). To confirm the interaction between CRN12_997 and SITCP14-2 while further assessing specificity, we performed the opposite experiment, where GFP-tagged CRN effectors and EV control were coexpressed with FLAG-tagged SITCP14-2 (Fig. 2B). These experiments confirmed that only CRN12_997 forms a complex with SITCP14-2 (Fig. 2B).

\section{Bimolecular fluorescence complementation confirms interaction between CRN12_997 and SITCP14-2 in the plant nucleus.}

To (i) independently verify that CRN12_997 and SITCP14-2 interact in vivo and (ii) show that this interaction takes place in the nucleus, we performed bimolecular fluorescence complementation (BiFC) experiments, in which we coexpressed CRN candidates fused to the $\mathrm{N}$-terminal half of yellow fluorescent protein (YFP) (pCL113::CRN) and YFP C terminus (pCL112:: $\mathrm{TCP}$ ). Because BiFC experiments are prone to false positives, especially in dense organelles like the nucleus, we included an unrelated CRN (CRN1_719) and EV controls. As expected, we found low levels of YFP signal in the nucleoplasm in all combinations (Supplementary Fig. S4). Given that we found YFP signal in multiple treatments, we quantified the level of reconstituted fluorescence between CRN-TCP combinations by counting the number of fluorescent nuclei per focal plane, using a standardized set of imaging parameters. This revealed that coexpression of CRN12_997 and SITCP14-2 results in significantly higher levels of fluorescence than any other combination (multiple $t$ tests, $P<10^{-5}$ ) (Supplementary Fig. S4A). 4',6-Diamidino-2-phenylindole staining confirmed that the reconstituted fluorescence emanates from the host nucleus (Supplementary Fig. S4B). Although we found differences in protein abundance levels between the $\mathrm{CRN}$ fusions and controls (Supplementary Fig. S4C), these do not correlate with the differences in YFP signal between BiFC treatment combinations. These observations show that there is strong reconstitution of YFP fluorescence in the nucleus, specifically with CRN12_997 and SITCP14-2 treatments.

\section{CRN12_997 alters subnuclear localization of SITCP14-2.}

Given that both CRN12_997 and SITCP14-2 accumulate and interact in the nucleus, we asked whether, at the subnuclear level, CRN12_997 and SITCP14-2 colocalize. We coexpressed EGFP-tagged CRN12_997, CRN125_11, and the EV control in combination with either tag-red fluorescent protein (tagRFP)S1TCP14-1 or tagRFP-SITCP14-2 and assessed localization in $N$. benthamiana. Both SITCP14-1 and SITCP14-2 coexpressed with EV, showed a distinct, speckled localization pattern 2 days after agroinfiltration (Fig. 3A and B; Supplementary Fig. S5). Interestingly, coexpression of CRN12_997 with SITCP14-2 abolished the characteristic nuclear speckle pattern (Fig. 3B), whereas the speckles remained visible with SITCP14-1 or when either SITCP14 homolog was coexpressed with CRN125_11 (Fig. 3A). Because coexpression of CRN125_11 did not affect SITCP14-2 localization, our results suggest that the CRN12_997 interaction with SITCP14-2 leads to the observed changes in target localization.

We investigated whether relocalization of SITCP14-2 occurs in cells during $P$. capsici infection and whether this could be attributed to pattern-triggered immunity (PTI) or ETS. We assessed this by localizing transiently expressed tagRFPSITCP14-2 in transgenic $N$. benthamiana leaves expressing ER-EGFP during $P$. capsici infection (Fig. 4). We identified cells that were in close proximity to $P$. capsici and assessed the number of nuclei expressing tagRFP-SITCP14-2, after which we determined subnuclear localization (Fig. 4). Similar to our colocalization results, SITCP14-2 exhibited diffuse nuclear 
localization in cells that were in proximity to $P$. capsici (Fig. $4 \mathrm{~A})$. These results contrasted with localization in noninfected tissues, where the speckled localization patterns were prevalent (Fig. 4A), suggesting that $P$. capsici infection alters SITCP14-2 localization. To exclude a role for PTI in relocalization, we challenged cells with $P$. capsici culture filtrate and assessed relocalization (Fig. 4A). Culture filtrate did not cause relocalization of SITCP14-2, suggesting that PTI does not trigger this phenotype. These results were robust because we found significant differences in the occurrence of relocalization between treatments after quantification (Fig. 4B). Collectively, these results suggest that SITCP14-2 relocalization is not attributable to (pathogen-associated molecular pattern-triggered) defense responses but, rather, $P$. capsici infection and, presumably, CRN12_997 effector activity.

\section{CRN12_997 dissociates TCP14-2 from chromatin.}

SITCP14-2 (transcriptional regulatory) activity will require DNA binding, which prompted us to ask whether its relocalization and inactivation in the presence of CRN12_997 is due to loss of DNA binding. For this purpose, we overexpressed combinations of CRN and SITCP14 and used a chromatin fractionation approach to separate chromatin-associated complexes from soluble proteins (Fig. 5). Chromatin fractionation on cells only expressing SITCP14-2 led to the copurification of SITCP14-2, suggesting DNA binding. Coexpression with CRN12_997 led to a marked reduction in chromatin-bound SITCP14-2 when compared with either the EV control or CRN125_11, suggesting that CRN12_997 mediated dissociation of SITCP14-2 (Fig. 5). Interestingly, a significant fraction of CRN12_997 copurified with chromatin, suggesting the direct displacement of the transcription factor from DNA (Fig. 5). These results strongly suggest that CRN12_997 activity causes SITCP14-2 dissociation from chromatin, providing a possible explanation for enhanced virulence in the presence of CRN12_997.

\section{DISCUSSION}

The plant immune signaling network comprises a vast and complex web of interconnected signaling cascades that collectively regulate defenses against most microbes.
Pathogens compromise host immunity by interfering with crucial signaling components or "hubs" to enhance pathogen virulence. Given that diverse pathogens such as nematodes, fungi, and bacteria can share host targets, it is not surprising that effectors and their functions are conserved between pathogen species (Lozano-Torres et al. 2012; Mukhtar et al. 2011; Song et al. 2009; Weßling et al. 2014). Additionally, pathogen effectors can evolve after a host jump (Dong et al. 2014), resulting in adaptations that preserve interactions with divergent targets, leading to complex mosaic pattern of host groups over time (Thines 2019).

Here, we provide multiple lines of evidence that effectortarget interactions identified between $H$. arabidopsidis CRN effectors and the Arabidopsis thaliana transcription factor AtTCP14 are preserved in the $P$. capsici-tomato interaction. Computational analyses helped identify two $P$. capsici CRN effectors (CRN12_997 and CRN125_11) and two tomato TCP14-like proteins (S1TCP14-1 and SITCP14-2), all of which were expressed in $P$. capsici and tomato, respectively.

Expression of SITCP14-2 (or NbTCP14-2) in N. benthamiana leaves reduced $P$. capsici infection and growth rates. These findings complement previously published work that shows that Arabidopsis knock-out plants, lacking TCP14, are more susceptible to filamentous pathogens (Mukhtar et al. 2011; Weßling et al. 2014). In addition to lesion size as an indicator of host susceptibility or immunity, we found that expression of SITCP14-2 also altered infection frequency and the onset of sporulation, important markers of immunity against Phytophthora spp. in plants (Hausbeck and Lamour 2004). We surmised that, if overexpression of SITCP14-2 and its closely related $N$. benthamiana homolog NbTCP14-2 enhanced immunity to $P$. capsici, coexpression of CRN12 997 could counteract this phenotype. Coexpression of CRN12_997, S1TCP14-2, and NbTCP14-2 specifically restored P. capsici growth, suggesting that CRN12_997 acts on SITCP14-2 and that this leads to reduced levels of resistance to $P$. capsici.

Given that CRN12_997 is expressed in P. capsici during infection, our results also suggest that endogenous levels of CRN12_997 are unable to sufficiently inactivate the host target, SITCP14-2, when the latter is overexpressed in planta. If true,

\begin{tabular}{rllllllllllllll} 
A INPUT & \multicolumn{1}{c}{ GFP-TCP14-1 } & + & + & + & - & - & - & + & + & + & \multicolumn{1}{c}{ ELUATE } \\
GFP-TCP14-2 & - & - & - & + & + & + & - & - & - & + & + & + \\
FLAG-CRN12_997 & - & - & + & - & - & + & - & - & + & - & - & + \\
FLAG-CRN125_11 & - & + & - & - & + & - & - & + & - & - & + & - \\
FLAG-CRN1_719 & + & - & - & + & - & - & + & - & - & + & - & -
\end{tabular}

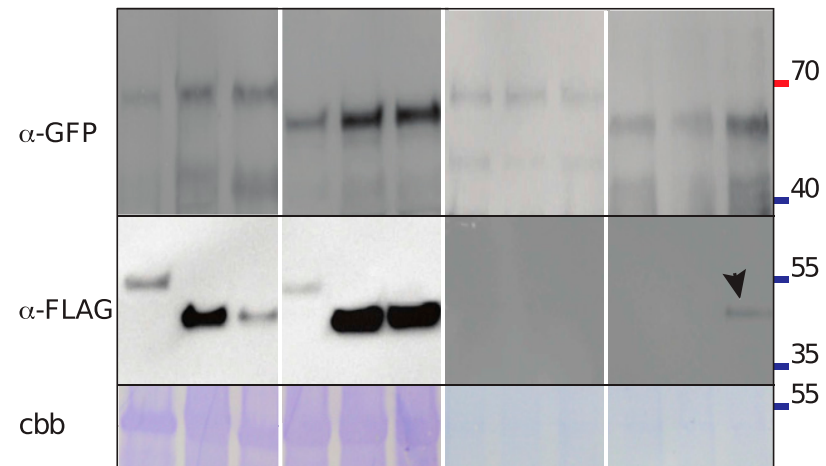

B

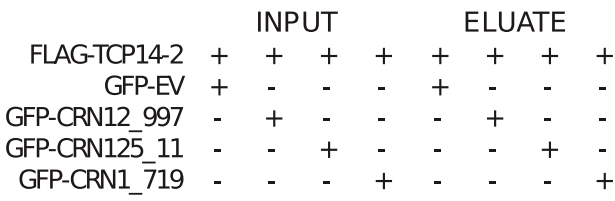

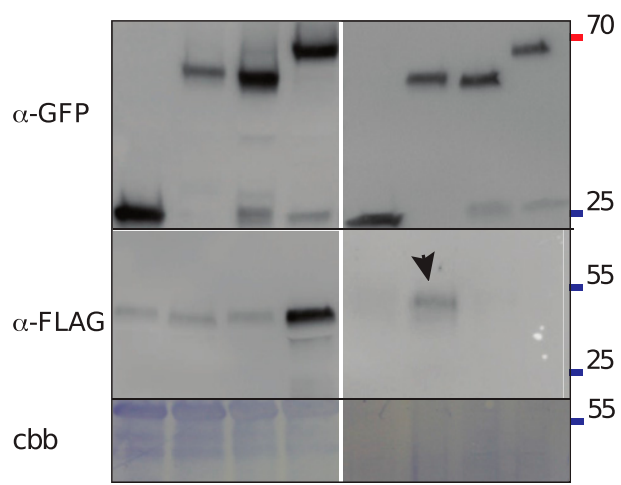

Fig. 2. Coimmunoprecipitation suggests a specific interaction between crinkling and necrosis (CRN)12_997 and S1TCP14-2. A, Green fluorescent protein (GFP)-tagged SITCP14-1 and SITCP14-2 were coexpressed with three FLAG-tagged CRN proteins in combinations as indicated (+ or -) and precipitated using magnetic anti-GFP beads. Inputs (left panel) and eluates (after boiling of beads) are shown. The specific signal for CRN12_997 is indicated with arrowheads. B, Reverse coimmunoprecipitation of GFP-tagged CRNs in the presence of FLAG-tagged SITCP14-2. Coexpression was performed as described in A and in combinations as indicated (+ or - ). The specific signal for SITCP14-2 is indicated with arrowheads. Size markers are indicated to denote protein size (in kilodaltons). 
and if higher SITCP14-2 levels are not detrimental to economically important agronomical traits, overexpression of a given target could help "inactivate" corresponding pathogen effectors in a bid to enhance immunity in crops. Thus, selecting (or generating) tomato varieties with elevated S1TCP14-2 levels could be a way to generate tomato varieties with enhanced resistance to $P$. capsici and possibly other Phytophthora spp.

To confirm the direct interaction between an effector and its target, we performed multiple independent coimmunoprecipitation experiments. We consistently copurified CRN12_997 and SITCP14-2, suggesting that the proteins form a complex in vivo. We independently affirmed these results through BiFC and FLIM-FRET experiments. In BiFC, we saw high fluorescence reconstitution only when we coexpressed CRN12_997 and SITCP14-2 and not with any of our negative controls. The lack of interaction between CRN125_11 and either TCP14-1 or TCP14-2 is particularly interesting. We hypothesize that this could be the result of divergent evolution. P. capsici is a broadhost-range pathogen and it is plausible that CRN125_11 targets TCP14 homologs in unrelated hosts such as members of the families Fabaceae or Cucurbitaceae.

The results of our work suggest that $P$. capsici (possibly along with other pathogens) employs a virulence strategy that, in part, relies on the modification of immune regulators that bind DNA. In recent years, strong evidence has emerged suggesting that effectors act as nucleomodulins (Bierne and Cossart 2012). This hypothesis is in line with the widely accepted view that chromatin remodeling and transcriptional reprogramming are crucial for both immunity and ETS. Large numbers of pathogen effectors localize to and function exclusively in the nucleus of the host cell (Caillaud et al.
A
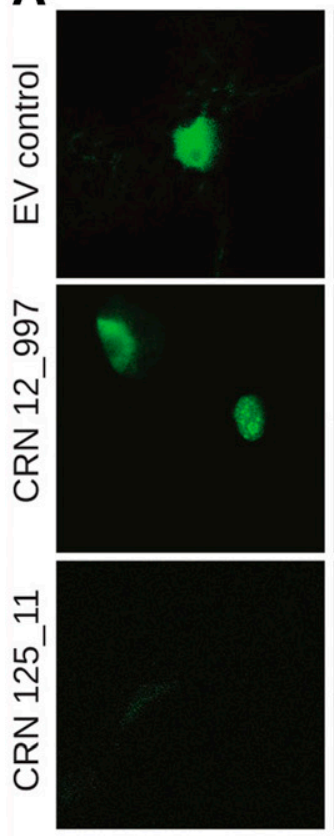

C
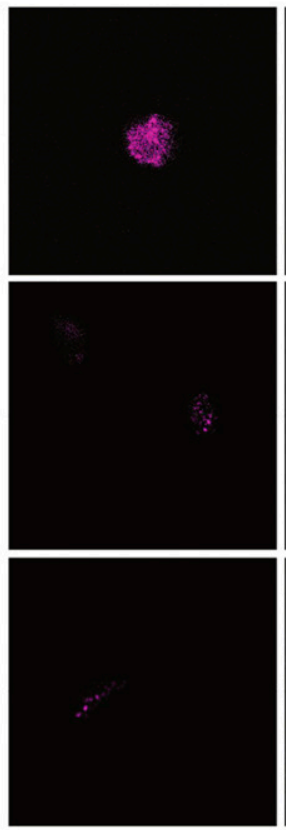

SITCP14-1

SITCP14-1 + EV
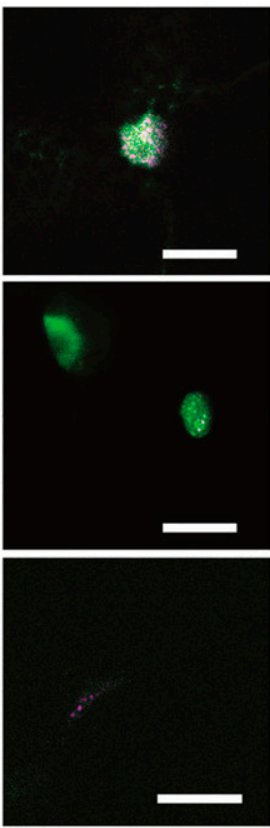

overlay
B
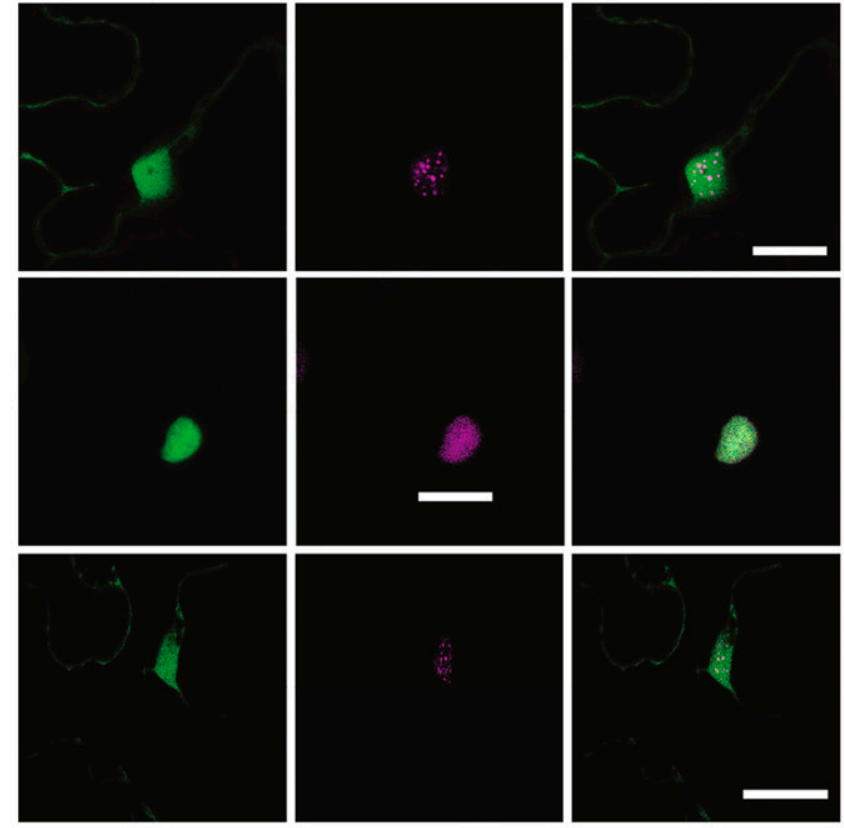

SITCP14-2

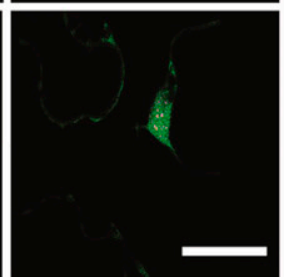

overlay

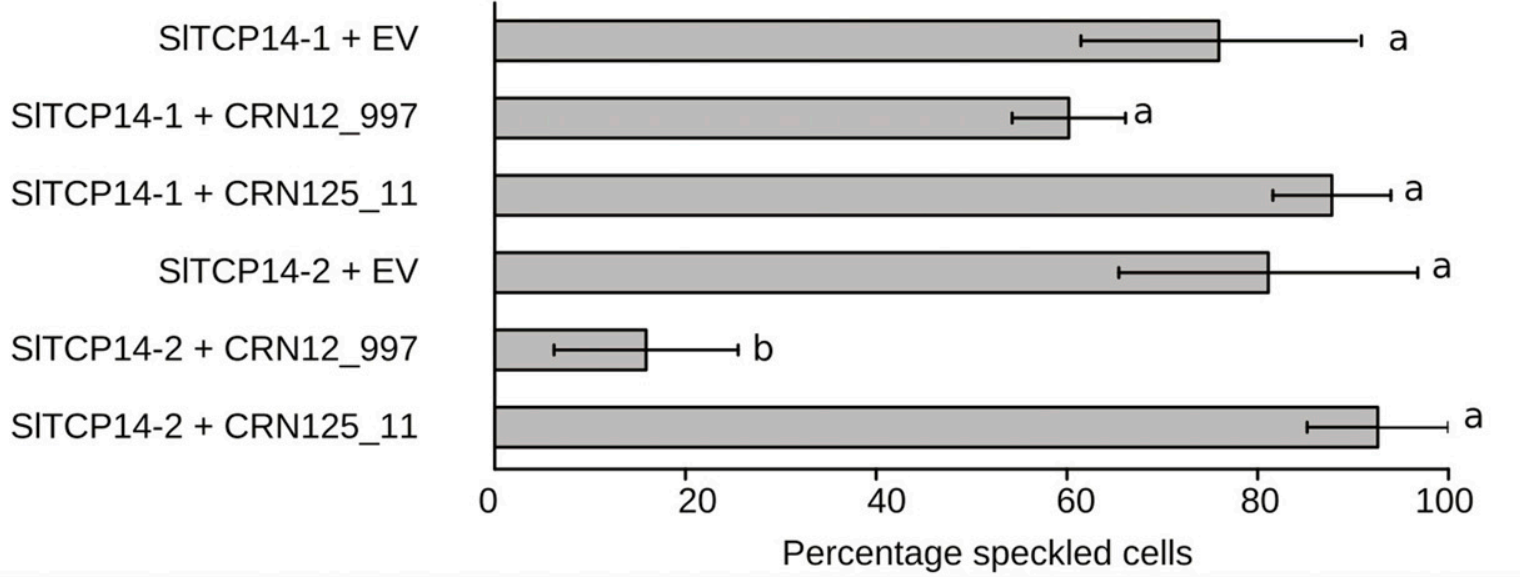

Fig. 3. Presence of crinkling and necrosis (CRN)12_997 results in alteration of SlTCP14-2 but not SlTCP14-1 localization. A, tag-Red fluorescent protein (tagRFP)-SITCP14-1 and B, tagRFPSITCP14-2 were ectopically expressed with enhanced green fluorescent protein (EGFP) and EGFP-tagged CRN12_997 and CRN125_11 as shown. EV = empty vector control. SlTCP14-1 and S1TCP14-2 localize as speckles in the nucleus but relocalize in the presence of CRN12_997 only. Left panels show EGFP, middle panels show tagRFP, and right panels show overlay images. Images show representative results obtained in multiple independent experiments. Zoomed-in versions of the middle panels are presented in Supplementary Figure S5. Scale bar $=10 \mu$ m. C, Percentage of cells showing speckled localization for SITCP14 variants. Bars marked with different lowercase letters are significantly different from each other (multiple $t$ tests, $P<0.05) ; n=110$. 
2012; Deslandes and Rivas 2011). TAL effectors from Xanthomonas spp. can bind DNA directly in a sequencespecific manner, activating the expression of host genes required for virulence in field conditions (Marois et al. 2002). AY-WB effector SAP11 binds directly to a CIN-TCP factor and destabilizes it to enhance virulence (Sugio et al. 2011, 2014).
It has also been demonstrated that two CRN effectors act as nucleomodulins. AeCRN13 binds to DNA and triggers DNA damage repair responses and host cell death (Ramirez-Garcés et al. 2016). PsCRN108 interferes with the production of HSPregulated defense responses by perturbing transcriptional activity at HSP promotors. Modulation at these sites by the effector may happen through specific DNA-binding events as

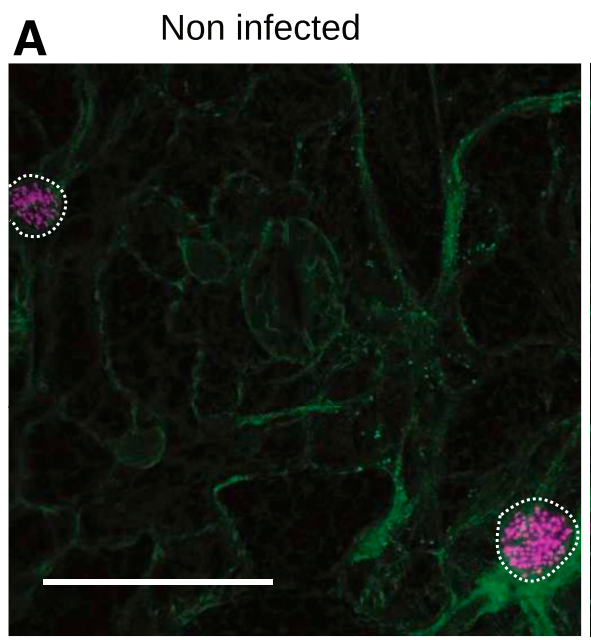

B Non infected

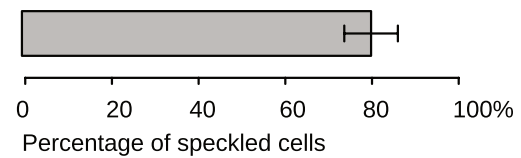

Infected

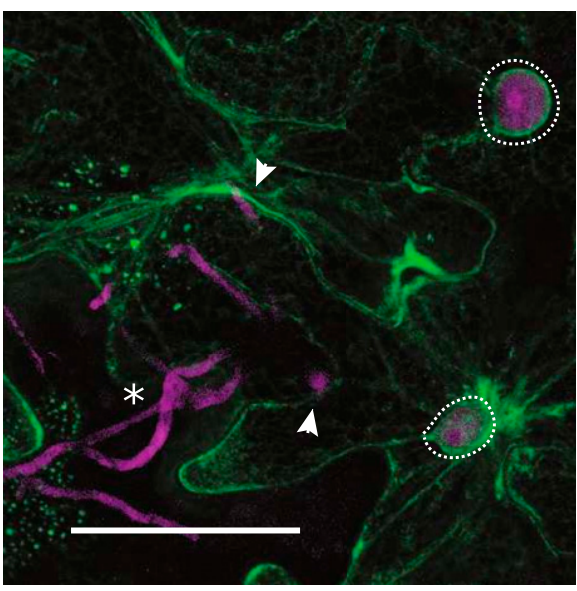

Infected

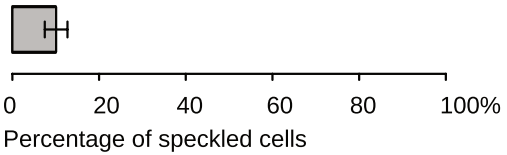

Culture Filtrate

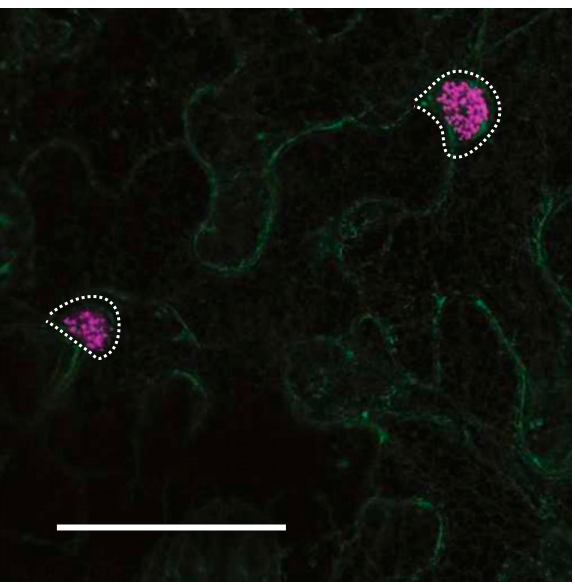

Culture Filtrate

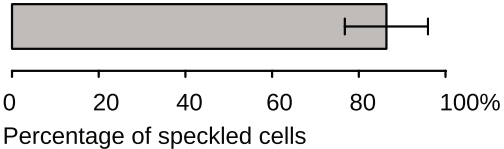

Fig. 4. Phytophthora capsici-infected cells show diffuse SITCP14-2 localization. A, tag-Red fluorescent protein (tagRFP)-SiTCP14-2 (magenta) was expressed in Nicotiana benthamiana leaf panels and can be observed inside the nuclei of the cells (dashed lines). Speckled localization can be observed in noninfected regions of the leaf (left panel). Following inoculation with $P$. capsici, tagRFP-SlTCP14-2 localization becomes diffuse in cells that are in close proximity to $P$. capsici (expressing TdTomato, also shown in magenta). The asterisk indicates the area with $P$. capsici growth. Arrowheads specifically show where $P$. capsici haustoria touch the cells that overexpress tagRFP-SITCP14-2. Infiltration with culture filtrate (pathogen-associated molecular pattern cocktail) does not have this effect. ER-enhanced green fluorescent protein (EGFP) (in green) was used as a marker to determine cell shape and viability. For infected samples, only living cells in proximity to $P$. capsici have been counted. Scale bar $=50 \mu \mathrm{m}$. B, Percentage of cells that show a speckled tagRFP-SITCP14-2 localization pattern. First, viable cells were selected based on ER-GFP localization, after which images were taken for analyses. Cells were selected based on the presence of SITCP14-2 and proximity to $P$. capsici structures (infected samples). Images and scoring was performed at 1 day postinfection. Error bars indicate standard errors. The percentage of speckled cells in noninfected and culture-filtrate-treated cells significantly differed from the percentage in infected cells $(t$ tests, $P<$ $0.001)$.

A

EGFP-SITCP14-2

FLAG-CRN12 997

FLAG-CRN125_11 total leaf extract

$$
-\quad-
$$

chromatin bound fraction

$$
+
$$$$
-
$$

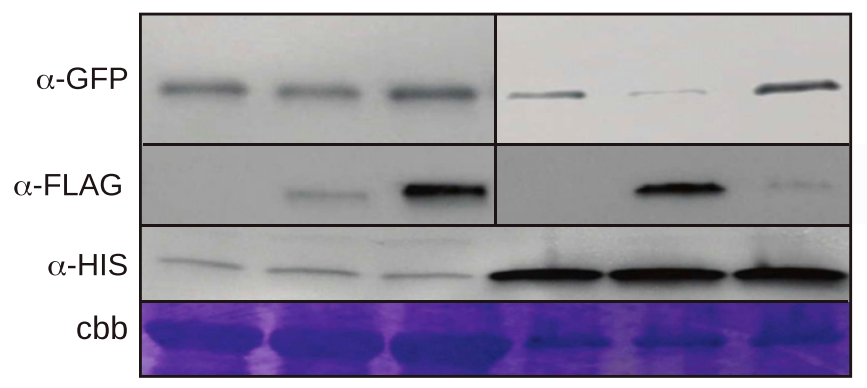

chromatin bound fraction

$\begin{array}{ccc}+ & + & + \\ - & - & - \\ - & + & - \\ - & - & +\end{array}$

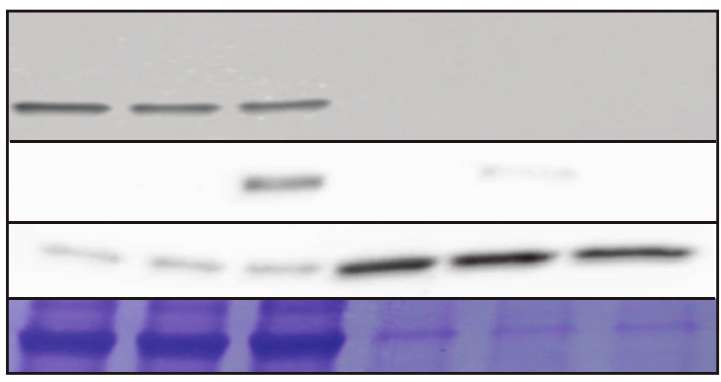

Fig. 5. SITCP14-2 binding to chromatin is reduced in the presence of crinkling and necrosis (CRN)12_997. A, Enhanced green fluorescent protein (EGFP)tagged SITCP14-2 was expressed alone or coexpressed with FLAG-tagged CRN12_997 or CRN125_11. The top panel shows expression of EGFP-tagged SITCP14-2 protein. The second panel shows FLAG-tagged CRN12_997 and CRN125_11. An anti-histone H3 blot and Coomassie (cbb) staining (lower panels) show equal loading between samples and evidence of chromatin enrichment (right panels) after fractionation from total leaf extracts (left panels). B, Free EGFP was expressed alone or together with CRN12_997 or CRN125_11. Absence of GFP signal in the chromatin bound fraction shows that there was no (or very little) contamination of soluble protein. The second panel shows FLAG-tagged CRN12_997 and CRN125_11. An anti-histone H3 blot and Coomassie (cbb) staining (lower panels) show equal loading between samples and evidence of chromatin enrichment (right panels) after fractionation from total leaf extracts (left panels). 
substitutions in the PsCRN108 HhH DNA-binding domains abolish function (Song et al. 2015).

We routinely identified CRN12_997 in chromatin-bound fractions in our assays, indicating that the effector associates with DNA either directly or through the formation of a complex with its protein target Sl-TCP14. Further investigation, employing assays that test for direct CRN-DNA binding, will help shed further light on effector function.

The alteration of SITCP14-2 activity is likely to result in transcriptional changes, some of which may occur in tomato upon infection. Such events could not only underpin the suppression of immune responses but also participate in wholesale transcriptional reprogramming of host gene expression, linked to pathogen lifestyles (Jupe et al. 2013). The observation that TCP14 is a target in both Arabidopsis and solanaceous plants for divergent pathogen species illustrates its importance in the immune signaling network. Knowing that resistance gene breeding methods are likely not able to provide durable resistance against Phytophthora spp. (Fry 2008; Stam and McDonald 2018), modification of TCP14 and its downstream targets represents an engineering strategy that could be applied in many crops to boost immunity against a wide range of pathogens.

\section{MATERIALS AND METHODS}

\section{Homologies and alignments.}

HpaRXCRN sequences were obtained from Mukhtar et al. (2011). Tomato homologs for AtTCP14 and P capsici CRN homologs were identified using BLASTn on the SOL genomics tomato database (SL2.40) and the Joint Genome Institute's P. capsici database (v11), respectively, (Lamour et al. 2012; The Tomato Genome Consortium 2012). A reciprocal best blast hit approach was taken to select candidate orthologs in tomato and $N$. benthamiana. SITCP14 and NbTCP14 sequences can be found in the supplementary materials. The $H$. arabidopsidis effectors were analyzed using the methods described previously (Stam et al. 2013b) to confirm that the domain structure of both $H$. arabidopsidis and P. capsici effectors was identical. Subsequently, all other CRNs with similar domain structure were extracted from Haas et al. (2009). Sequences were truncated after the HVLVVP sequence containing the DWL domain (Supplementary File S1) and aligned using MUSCLE (Edgar 2004). A maximum-likelihood tree was created with PhyML and visualized with TreeDyn (Dereeper et al. 2008). A conservation motif was drawn using jalview (Waterhouse et al. 2009). TCPs were aligned using MUSCLE. Tomato TCP expression data were obtained from microarray data generated from a $P$. capsici-tomato time-course infection experiment published previously (Jupe et al. 2013; Stam et al. 2013a).

\section{Disease assays.}

Leaves were harvested 3 days after infiltration and collected in 1.5-cm-deep collection trays containing wet tissue paper. For infection assays, we placed 10- $\mu$ d droplets of a zoospore solution $(50,000$ or 500 spores $/ \mathrm{ml})$ on the lower side of each leaf. We used $P$. capsici strain LT1534 for all of our assays. The trays were stored in an incubator under $16 \mathrm{~h}$ of light and set at $26^{\circ} \mathrm{C}$ by day and $22^{\circ} \mathrm{C}$ by night. Lesion diameters were measured 2 days postinoculation as previously described (Rodriguez et al. 2014; Stam et al. 2013b). For spore count assays, we sampled leaf discs (14 $\mathrm{mm}$ in diameter) from the center of the infiltration region at $3 \mathrm{dpi}$. The discs were resuspended in $250 \mu \mathrm{l}$ of water and the number of spores was counted in five $2-\mu$ droplets, after which the average spore count per disc was calculated. For determination of infection frequency, lesion formation was assessed $1 \mathrm{dpi}$ and percent infection determined by (number of lesions/number of inoculations $) \times 100$. Detached leaves from $N$. benthamiana plants expressing ER-targeted GFP were infected with droplets of $P$. capsici expressing TdTomato and imaged 16 to $24 \mathrm{~h}$ after infection. CF treatment was imaged 4 to $8 \mathrm{~h}$ postinfiltration and prepared as described before (Stam et al. 2013a). All statistical test results reported in this study were obtained in $\mathrm{R}$ and corrected for multiple testing using Bonferroni correction with the p.adjust() function.

\section{Transient expression and localization.}

SITCP14 genes were amplified from tomato cDNA extracted from plants of the variety Money Maker, infected with $P$. capsici strain LT1534. RNA was extracted at $0,8,24$, and $48 \mathrm{~h}$ postinfection and pooled, and cDNA was generated using Life Technologies Superscript II RTase. PCR amplicons were transferred into pENTR-D-TOPO vector (Life Technologies) and shuttled into the appropriate destination vectors, as mentioned below. The $N$. benthamiana TCP14 homolog was cloned from cDNA derived from RNA extracted from similarly treated $N$. benthamiana leaves, using the cloning strategy described above. Primers used in this study are listed in Supplementary File S1. CRN effectors were previously cloned from cDNA extracted from similarly treated tissue (Stam et al. 2013a). For colocalization, pB7WGF2 plasmids containing EGFP-CRN Cterminal construct fusions and pGWB461 plasmids containing tagRFP-SITCP14 fusions were transformed into Agrobacterium tumefaciens strain AGL1. For BiFC, CRN and TCP constructs were transformed into pCL112 and pCL113. Transformants were grown on Luria-Bertani medium containing rifampicin and spectinomycin. A single colony was grown overnight and resuspended in infiltration buffer $(10 \mathrm{mM} \mathrm{MgCl}, 150 \mu \mathrm{M}$ acetosyringone) to an optical density at $600 \mathrm{~nm}\left(\mathrm{OD}_{600}\right)$ of 0.1 . Plants were grown in a glasshouse under $16 \mathrm{~h}$ of light and temperatures of $26^{\circ} \mathrm{C}$ by day and $22^{\circ} \mathrm{C}$ by night. $N$. benthamiana leaves transiently expressing the construct of interest were harvested for microscopy 2 days after infiltration. To maintain cell viability and improve optical properties after detachment, the leaves were infiltrated with water before mounting on a microscope slide. Leaf samples were imaged using a Leica SP2 confocal microscope. Peak excitation and emission wavelengths were 514 and $527 \mathrm{~nm}$ for YFP, 488 and $509 \mathrm{~nm}$ for GFP, and 561 and $607 \mathrm{~nm}$ for tagRFP, respectively. All microscopy experiments were repeated independently to generate at least four replicates.

\section{Protein extraction, coimmunoprecipitation, and Western blot.}

Agrobacterium carrying FLAG-tagged or GFP-tagged constructs (vectors pGBW12 and pB7WGF2, respectively) were resuspended in infiltration buffer $(10 \mathrm{mM} \mathrm{MgCl})$ to an $\mathrm{OD}_{600}$ of 0.5 . This suspension was mixed in a $1: 1$ ratio with a simultaneously prepared suspension of Agrobacterium cells carrying the silencing suppressor P19. The resulting Agrobacterium preparations were infiltrated into 4- to 5-week-old $N$. benthamiana leaves. Tissues were harvested 3 days after infiltration. Leaves were ground in liquid nitrogen and leaf powder was resuspended in GTEN buffer (10\% glycerol, $25 \mathrm{mM}$ Tris, $1 \mathrm{mM}$ EDTA, and $150 \mathrm{mM} \mathrm{NaCl} ; \mathrm{pH}$ 7.4) supplemented with $2 \%$ polyvinylpolypyrrolidone, $10 \mathrm{mM}$ dithiothreitol, and $1 \times$ complete protease inhibitor cocktail (Thermo Scientific). Coimmunoprecipitation was done using GFP-trap (Chromotek), following the manufacturer's instructions. All samples were run on 4 to $20 \%$ TGX polyacrylamide gel electrophoresis gels (Bio-Rad) before transfer to polyvinylidene difluoride membranes using a Bio-Rad transblot system. Blots were blocked for 30 min with $5 \%$ milk in Tris-buffered saline with Tween (TBS-T) $(0.1 \%$ Tween), and probed with mouse anti-FLAG antibodies (Santa 
Cruz Biotech) (1:4000) or mouse anti GFP antibody (Santa Cruz Biotech) (1:5000). FLAG and GFP blots were then probed with secondary antimouse-HRP antibodies (1:40.000). BiFC constructs were extracted similarly and probed with anti-HA (pCL113) or anti-Myc (pCL112) HRP-conjugated antibodies (1:500) (Genscript). All blots were washed three to four times in TBS-T for 5 min before incubation with Millipore Luminata Forte substrate or SuperSignal West Pico (Thermo Scientific). Blots were imaged on a Syngene G:BOX XT4 Imager.

\section{Chromatin fractionation.}

Tagged candidate proteins were overexpressed in $N$. benthamiana as described above. Ground leaf tissue was suspended in $10 \mathrm{ml}$ of ice-cold buffer $\left(10 \mathrm{mM}\right.$ piperazine- $N, N^{\prime}$ bis(2-ethanesulfonic acid), $10 \mathrm{mM} \mathrm{KCl}, 1.5 \mathrm{mM} \mathrm{MgCl}_{2}$, $340 \mathrm{mM}$ sucrose, $10 \%$ glycerol, $0.5 \%$ Triton $\mathrm{X}-100$, and $1 \times$ SIGMAFAST protease inhibitor cocktail [Sigma-Aldrich]; $\mathrm{pH}$ 6.8) and filtered through Miracloth (Calbiochem). A 6-ml aliquot of this whole cell extract was taken and centrifuged at $3,000 \times g$ for $10 \mathrm{~min}$ at $4^{\circ} \mathrm{C}$. Then, $1 \mathrm{ml}$ of TCA-a $(10 \mathrm{ml}$ of acetone, $2 \mathrm{ml}$ of tricarboxylic acid [trichloroacetic acid; $20 \%$ $\{\mathrm{wt} / \mathrm{vol}\}$ in $\mathrm{H}_{2} \mathrm{O}$ ], and $8 \mu \mathrm{l}$ of $\beta$-mercaptoethanol) was used to resuspend the pellet, containing chromatin bound proteins. After brief vortexing, these samples were stored at $-20^{\circ} \mathrm{C}$ for $1 \mathrm{~h}$. Samples were centrifuged at $16,000 \times g$ for $30 \mathrm{~min}$ at $4^{\circ} \mathrm{C}$ and the resulting pellets were washed three times with $\mathrm{a} / \beta$-me solution ( $8 \mu \mathrm{l}$ of $\beta$-mercaptoethanol in $10 \mathrm{ml}$ of acetone) before resuspending in $100 \mu \mathrm{l}$ of sodium dodecyl sulfate loading buffer.

\section{ACKNOWLEDGMENTS}

We thank all Huitema lab members for constructive feedback on our work and The James Hutton Institute, where P. capsici cultures were held under license PH\6\2015.

\section{AUTHOR-RECOMMENDED INTERNET RESOURCE}

TreeDyn: http://phylogeny.lirmm.fr/phylo_cgi/index.cgi

\section{LITERATURE CITED}

Amaro, T. M. M. M., Thilliez, G. J. A., McLeod, R. A., and Huitema, E. 2018. Random mutagenesis screen shows that Phytophthora capsici CRN83_152-mediated cell death is not required for its virulence function(s). Mol. Plant Pathol. 19:1114-1126.

Amaro, T. M. M. M., Thilliez, G. J. A., Motion, G. B., and Huitema, E. 2017. A perspective on CRN proteins in the genomics age: Evolution, classification, delivery and function revisited. Front. Plant Sci. 8:99 https://www.frontiersin.org/articles/10.3389/fpls.2017.00099/full.

Arabidopsis Interactome Mapping Consortium. 2011. Evidence for network evolution in an Arabidopsis interactome map. Science 333:601-607.

Baxter, L., Tripathy, S., Ishaque, N., Boot, N., Cabral, A., Kemen, E., Thines, M., Ah-Fong, A., Anderson, R., Badejoko, W., Bittner-Eddy, P., Boore, J. L., Chibucos, M. C., Coates, M., Dehal, P., Delehaunty, K., Dong, S., Downton, P., Dumas, B., Fabro, G., Fronick, C., Fuerstenberg, S. I., Fulton, L., Gaulin, E., Govers, F., Hughes, L., Humphray, S., Jiang, R. H. Y., Judelson, H., Kamoun, S., Kyung, K., Meijer, H., Minx, P. Morris, P., Nelson, J., Phuntumart, V., Qutob, D., Rehmany, A., RougonCardoso, A., Ryden, P., Torto-Alalibo, T., Studholme, D., Wang, Y., Win, J., Wood, J., Clifton, S. W., Rogers, J., Van den Ackerveken, G., Jones, J. D. G., McDowell, J. M., Beynon, J., and Tyler, B. M. 2010. Signatures of adaptation to obligate biotrophy in the Hyaloperonospora arabidopsidis genome. Science 330:1549-1551.

Bierne, H., and Cossart, P. 2012. When bacteria target the nucleus: The emerging family of nucleomodulins. Cell. Microbiol. 14:622-633.

Caillaud, M.-C., Piquerez, S. J. M., Fabro, G., Steinbrenner, J., Ishaque, N., Beynon, J., and Jones, J. D. G. 2012. Subcellular localization of the Hpa RxLR effector repertoire identifies a tonoplast-associated protein HaRxL17 that confers enhanced plant susceptibility. Plant J. 69: 252-265

Carella, P., Evangelisti, E., and Schornack, S. 2018. Sticking to it: Phytopathogen effector molecules may converge on evolutionarily conserved host targets in green plants. Curr. Opin. Plant Biol. 44: 175-180.

Cubas, P., Lauter, N., Doebley, J., and Coen, E. 1999. The TCP domain: A motif found in proteins regulating plant growth and development. Plant J. 18:215-222.

Dereeper, A., Guignon, V., Blanc, G., Audic, S., Buffet, S., Chevenet, F., Dufayard, J. F., Guindon, S., Lefort, V., Lescot, M., Claverie, J. M., and Gascuel, O. 2008. Phylogeny.fr: Robust phylogenetic analysis for the non-specialist. Nucleic Acids Res. 36:W465-W469.

Deslandes, L., and Rivas, S. 2011. The plant cell nucleus. Plant Signal. Behav. 6:42-48.

Dong, S., Stam, R., Cano, L. M., Song, J., Sklenar, J., Yoshida, K., Bozkurt, T. O., Oliva, R., Liu, Z., Tian, M., Win, J., Banfield, M. J., Jones, A. M., van der Hoorn, R. A., and Kamoun, S. 2014. Effector specialization in a lineage of the Irish potato famine pathogen. Science 343:552-555.

Edgar, R. C. 2004. MUSCLE: Multiple sequence alignment with high accuracy and high throughput. Nucleic Acids Res. 32:1792-1797.

Fisher, M. C., Henk, D. A., Briggs, C. J., Brownstein, J. S., Madoff, L. C., McCraw, S. L., and Gurr, S. J. 2012. Emerging fungal threats to animal, plant and ecosystem health. Nature 484:186-194.

Fry, W. 2008. Phytophthora infestans: The plant (and R gene) destroyer. Mol. Plant Pathol. 9:385-402.

Gassmann, W., and Bhattacharjee, S. 2012. Effector-triggered immunity signaling: From gene-for-gene pathways to protein-protein interaction networks. Mol. Plant-Microbe Interact. 25:862-868.

Gaulin, E., Madoui, M.-A. A., Bottin, A., Jacquet, C., Mathé, C., Couloux, A., Wincker, P., and Dumas, B. 2008. Transcriptome of Aphanomyces euteiches: New oomycete putative pathogenicity factors and metabolic pathways. PLoS One 3:e1723.

Haas, B. J., Kamoun, S., Zody, M. C., Jiang, R. H. Y., Handsaker, R. E., Cano, L. M., Grabherr, M., Kodira, C. D., Raffaele, S., Torto-Alalibo, T., Bozkurt, T. O., Ah-Fong, A. M., Alvarado, L., Anderson, V. L., Armstrong, M. R., Avrova, A., Baxter, L., Beynon, J., Boevink, P. C., Bollmann, S. R., Bos, J. I., Bulone, V., Cai, G., Cakir, C., Carrington, J. C., Chawner, M., Conti, L., Costanzo, S., Ewan, R., Fahlgren, N., Fischbach, M. A., Fugelstad, J., Gilroy, E. M., Gnerre, S., Green, P. J., Grenville-Briggs, L. J., Griffith, J., Grünwald, N. J., Horn, K., Horner N. R., Hu, C. H., Huitema, E., Jeong, D. H., Jones, A. M., Jones, J. D., Jones, R. W., Karlsson, E. K., Kunjeti, S. G., Lamour, K., Liu, Z., Ma, L., Maclean, D., Chibucos, M. C., McDonald, H., McWalters, J., Meijer, H. J., Morgan, W., Morris, P. F., Munro, C. A., O’Neill, K., OspinaGiraldo, M., Pinzón, A., Pritchard, L., Ramsahoye, B., Ren, Q., Restrepo, S., Roy, S., Sadanandom, A., Savidor, A., Schornack, S., Schwartz, D. C., Schumann, U. D., Schwessinger, B., Seyer, L., Sharpe, T., Silvar, C., Song, J., Studholme, D. J., Sykes, S., Thines, M., van de Vondervoort, P. J., Phuntumart, V., Wawra, S., Weide, R., Win, J., Young, C., Zhou, S., Fry, W., Meyers, B. C., van West, P., Ristaino, J., Govers, F., Birch, P. R., Whisson, S. C., Judelson, H. S., and Nusbaum, C. 2009. Genome sequence and analysis of the Irish potato famine pathogen Phytophthora infestans. Nature 461:393-398.

Hausbeck, M. K., and Lamour, K. H. 2004. Phytophthora capsici on vegetable crops: Research progress and management challenges. Plant Dis. 88:1292-1303.

Hogenhout, S. A., Van der Hoorn, R. A. L., Terauchi, R., and Kamoun, S. 2009. Emerging concepts in effector biology of plant-associated organisms. Mol. Plant-Microbe Interact. 22:115-122.

Jones, J. D. G., and Dangl, J. L. 2006. The plant immune system. Nature 444:323-329

Jupe, J., Stam, R., Howden, A. J. M., Morris, J. A., Zhang, R., Hedley, P. E., and Huitema, E. 2013. Phytophthora capsici-tomato interaction features dramatic shifts in gene expression associated with a hemi-biotrophic lifestyle. Genome Biol. 14:R63.

Kieffer, M., Master, V., Waites, R., and Davies, B. 2011. TCP14 and TCP15 affect internode length and leaf shape in Arabidopsis. Plant J. 68 147-158.

Kim, S. H., Son, G. H., Bhattacharjee, S., Kim, H. J., Nam, J. C., Nguyen, P. D. T., Hong, J. C., and Gassmann, W. 2014. The Arabidopsis immune adaptor SRFR1 interacts with TCP transcription factors that redundantly contribute to effector-triggered immunity. Plant J. 78:978-989.

Kosugi, S., and Ohashi, Y. 1997. PCF1 and PCF2 specifically bind to cis elements in the rice proliferating cell nuclear antigen gene. Plant Cell 9: 1607-1619.

Lamour, K. H., Mudge, J., Gobena, D., Hurtado-Gonzales, O. P., Schmutz, J., Kuo, A., Miller, N. A., Rice, B. J., Raffaele, S., Cano, L. M., Bharti, A. K., Donahoo, R. S., Finley, S., Huitema, E., Hulvey, J., Platt, D., Salamov, A., Savidor, A., Sharma, R., Stam, R., Storey, D., Thines, M. Win, J., Haas, B. J., Dinwiddie, D. L., Jenkins, J., Knight, J. R., Affourtit, J. P., Han, C. S., Chertkov, O., Lindquist, E. A., Detter, C., Grigoriev, 
I. V., Kamoun, S., and Kingsmore, S. F. 2012. Genome sequencing and mapping reveal loss of heterozygosity as a mechanism for rapid adaptation in the vegetable pathogen Phytophthora capsici. Mol. PlantMicrobe Interact. 25:1350-1360.

Lévesque, C. A., Brouwer, H., Cano, L., Hamilton, J. P., Holt, C., Huitema E., Raffaele, S., Robideau, G. P., Thines, M., Win, J., Zerillo, M. M., Beakes, G. W., Boore, J. L., Busam, D., Dumas, B., Ferriera, S., Fuerstenberg, S. I., Gachon, C. M., Gaulin, E., Govers, F., GrenvilleBriggs, L., Horner, N., Hostetler, J., Jiang, R. H., Johnson, J., Krajaejun, T., Lin, H., Meijer, H. J., Moore, B., Morris, P., Phuntmart, V., Puiu, D., Shetty, J., Stajich, J. E., Tripathy, S., Wawra, S., van West, P., Whitty, B. R., Coutinho, P. M., Henrissat, B., Martin, F., Thomas, P. D., Tyler, B. M., De Vries, R. P., Kamoun, S., Yandell, M., Tisserat, N., and Buell, C. R. 2010. Genome sequence of the necrotrophic plant pathogen Pythium ultimum reveals original pathogenicity mechanisms and effector repertoire. Genome Biol. 11:R73.

Li, Q., Zhang, M., Shen, D., Liu, T., Chen, Y., Zhou, J.-M., and Dou, D. 2016. A Phytophthora sojae effector PsCRN63 forms homo-/heterodimers to suppress plant immunity via an inverted association manner. Sci. Rep. 6:26951.

Links, M. G., Holub, E., Jiang, R. H. Y., Sharpe, A. G., Hegedus, D., Beynon, E., Sillito, D., Clarke, W. E., Uzuhashi, S., and Borhan, M. H. 2011. De novo sequence assembly of Albugo candida reveals a small genome relative to other biotrophic oomycetes. BMC Genomics 12: 503.

Liu, T., Ye, W., Ru, Y., Yang, X., Gu, B., Tao, K., Lu, S., Dong, S., Zheng, X., Shan, W., Wang, Y., and Dou, D. 2011. Two host cytoplasmic effectors are required for pathogenesis of Phytophthora sojae by suppression of host defenses. Plant Physiol. 155:490-501.

Lozano-Torres, J. L., Wilbers, R. H. P., Gawronski, P., Boshoven, J. C., Finkers-Tomczak, A., Cordewener, J. H. G., America, A. H., Overmars, H. A., Van 't Klooster, J. W., Baranowski, L., Sobczak, M., Ilyas, M., van der Hoorn, R. A., Schots, A., de Wit, P. J., Bakker, J., Goverse, A., and Smant, G. 2012. Dual disease resistance mediated by the immune receptor $\mathrm{Cf}-2$ in tomato requires a common virulence target of a fungus and a nematode. Proc. Natl. Acad. Sci. U.S.A. 109:10119-10124.

Ma, K.-W., Flores, C., and Ma, W. 2011. Chromatin configuration as a battlefield in plant-bacteria interactions. Plant Physiol. 157:535-543.

Marois, E., Van den Ackerveken, G., and Bonas, U. 2002. The Xanthomonas type III effector protein AvrBs3 modulates plant gene expression and induces cell hypertrophy in the susceptible host. Mol. Plant-Microbe Interact. 15:637-646.

Maximo, H. J., Dalio, R. J. D., Dias, R. O., Litholdo, C. G., Jr., Felizatti, H. L., and Machado, M. A. 2019. PpCRN7 and PpCRN20 of Phytophthora parasitica regulate plant cell death leading to enhancement of host susceptibility. BMC Plant Biol. 19:544.

Mukhtar, M. S., Carvunis, A.-R., Dreze, M., Epple, P., Steinbrenner, J., Moore, J., Tasan, M., Galli, M., Hao, T., Nishimura, M. T., Pevzner, S. J., Donovan, S. E., Ghamsari, L., Santhanam, B., Romero, V., Poulin, M. M., Gebreab, F., Gutierrez, B. J., Tam, S., Monachello, D., Boxem, M., Harbort, C. J., McDonald, N., Gai, L., Chen, H., He, Y., European Union Effectoromics Consortium, Vandenhaute, J., Roth, F. P., Hill, D. E., Ecker, J. R., Vidal, M., Beynon, J., Braun, P., and Dangl, J. L. 2011. Independently evolved virulence effectors converge onto hubs in a plant immune system network. Science 333:596-601.

Pritchard, L., and Birch, P. 2011. A systems biology perspective on plantmicrobe interactions: Biochemical and structural targets of pathogen effectors. Plant Sci. 180:584-603.

Ramirez-Garcés, D., Camborde, L., Pel, M. J. C., Jauneau, A., Martinez, Y., Néant, I., Leclerc, C., Moreau, M., Dumas, B., and Gaulin, E. 2016. CRN13 candidate effectors from plant and animal eukaryotic pathogens are DNA-binding proteins which trigger host DNA damage response. New Phytol. 210:602-617.

Rodriguez, P. A., Stam, R., Warbroek, T., and Bos, J. I. B. 2014. Mp10 and Mp42 from the aphid species Myzus persicae trigger plant defenses in Nicotiana benthamiana through different activities. Mol. Plant-Microbe Interact. 27:30-39.

Schornack, S., Huitema, E., Cano, L. M., Bozkurt, T. O., Oliva, R., Van Damme, M., Schwizer, S., Raffaele, S., Chaparro-Garcia, A., Farrer, R., Segretin, M. E., Bos, J., Haas, B. J., Zody, M. C., Nusbaum, C., Win, J., Thines, M., and Kamoun, S. 2009. Ten things to know about oomycete effectors. Mol. Plant Pathol. 10:795-803.

Schornack, S., van Damme, M., Bozkurt, T. O., Cano, L. M., Smoker, M., Thines, M., Gaulin, E., Kamoun, S., and Huitema, E. 2010. Ancient class of translocated oomycete effectors targets the host nucleus. Proc. Natl. Acad. Sci. U.S.A. 107:17421-17426.
Song, J., Win, J., Tian, M., Schornack, S., Kaschani, F., Ilyas, M., van der Hoorn, R. A., and Kamoun, S. 2009. Apoplastic effectors secreted by two unrelated eukaryotic plant pathogens target the tomato defense protease Rcr3. Proc. Natl. Acad. Sci. U.S.A. 106:1654-1659.

Song, T., Ma, Z., Shen, D., Li, Q., Li, W., Su, L., Ye, T., Zhang, M., Wang, Y., and Dou, D. 2015. An Oomycete CRN Effector Reprograms Expression of Plant HSP Genes by Targeting their Promoters. PLoS Pathog. 11:e1005348.

Spoel, S. H., and Dong, X. 2012. How do plants achieve immunity? Defence without specialized immune cells. Nat. Rev. Immunol. 12: 89-100.

Stam, R., Howden, A. J. M., Delgado-Cerezo, M., M M Amaro, T. M., Motion, G. B., Pham, J., and Huitema, E. 2013a. Characterization of cell death inducing Phytophthora capsici CRN effectors suggests diverse activities in the host nucleus. Front. Plant Sci. 4:387.

Stam, R., Jupe, J., Howden, A. J. M., Morris, J. A., Boevink, P. C., Hedley, P. E., and Huitema, E. 2013b. Identification and characterisation of CRN effectors in Phytophthora capsici shows modularity and functional diversity. PLoS One 8:e59517.

Stam, R., and McDonald, B. A. 2018. When resistance gene pyramids are not durable-the role of pathogen diversity. Mol. Plant Pathol. 19: 521-524.

Steiner, E., Yanai, O., Efroni, I., Ori, N., Eshed, Y., and Weiss, D. 2012. Class I TCPs modulate cytokinin-induced branching and meristematic activity in tomato. Plant Signal. Behav. 7:807-810.

Sugio, A., Kingdom, H. N., MacLean, A. M., Grieve, V. M., and Hogenhout, S. A. 2011. Phytoplasma protein effector SAP11 enhances insect vector reproduction by manipulating plant development and defense hormone biosynthesis. Proc. Natl. Acad. Sci. U.S.A. 108: E1254-E1263.

Sugio, A., MacLean, A. M., and Hogenhout, S. A. 2014. The small phytoplasma virulence effector SAP11 contains distinct domains required for nuclear targeting and CIN-TCP binding and destabilization. New Phytol. 202:838-848.

The Tomato Genome Consortium. 2012. The tomato genome sequence provides insights into fleshy fruit evolution. Nature 485:635-641.

Thines, M. 2019. An evolutionary framework for host shifts-Jumping ships for survival. New Phytol. 224:605-617.

Tyler, B. M. 2007. Phytophthora sojae: Root rot pathogen of soybean and model oomycete. Mol. Plant Pathol. 8:1-8.

Tyler, B. M., Tripathy, S., Zhang, X., Dehal, P., Jiang, R. H. Y., Aerts, A., Arredondo, F. D., Baxter, L., Bensasson, D., Beynon, J. L., Chapman, J., Damasceno, C. M., Dorrance, A. E., Dou, D., Dickerman, A. W., Dubchak, I. L., Garbelotto, M., Gijzen, M., Gordon, S. G., Govers, F., Grunwald, N. J., Huang, W., Ivors, K. L., Jones, R. W., Kamoun, S., Krampis, K., Lamour, K. H., Lee, M. K., McDonald, W. H., Medina, M., Meijer, H. J., Nordberg, E. K., Maclean, D. J., Ospina-Giraldo, M. D., Morris, P. F., Phuntumart, V., Putnam, N. H., Rash, S., Rose, J. K., Sakihama, Y., Salamov, A. A., Savidor, A., Scheuring, C. F., Smith, B. M., Sobral, B. W., Terry, A., Torto-Alalibo, T. A., Win, J., Xu, Z., Zhang, H., Grigoriev, I. V., Rokhsar, D. S., and Boore, J. L. 2006. Phytophthora genome sequences uncover evolutionary origins and mechanisms of pathogenesis. Science 313:1261-1266.

van Damme, M., Bozkurt, T. O., Cakir, C., Schornack, S., Sklenar, J., Jones, A. M. E., and Kamoun, S. 2012. The Irish potato famine pathogen Phytophthora infestans translocates the CRN8 kinase into host plant cells. PLoS Pathog. 8:e1002875.

Viola, I. L., Guttlein, L. N., and Gonzalez, D. H. 2013. Redox modulation of plant developmental regulators from the class I TCP transcription factor family. Plant Physiol. 162:1434-1447.

Waterhouse, A. M., Procter, J. B., Martin, D. M. A., Clamp, M., and Barton, G. J. 2009. Jalview Version 2-A multiple sequence alignment editor and analysis workbench. Bioinformatics 25:1189-1191.

Weßling, R., Epple, P., Altmann, S., He, Y., Yang, L., Henz, S. R., McDonald, N., Wiley, K., Bader, K. C., Gläßer, C., Mukhtar, M. S., Haigis, S., Ghamsari, L., Stephens, A. E., Ecker, J. R., Vidal, M., Jones, J. D., Mayer, K. F., Ver Loren van Themaat, E., Weigel, D., Schulze-Lefert, P., Dangl, J. L., Panstruga, R., and Braun, P. 2014. Convergent targeting of a common host protein-network by pathogen effectors from three kingdoms of life. Cell Host Microbe 16:364-375.

Yang, L., Teixeira, P. J. P. L., Biswas, S., Finkel, O. M., He, Y., SalasGonzalez, I., English, M. E., Epple, P., Mieczkowski, P., and Dangl, J. L. 2017. Pseudomonas syringae Type III Effector HopBB1 Promotes Host Transcriptional Repressor Degradation to Regulate Phytohormone Responses and Virulence. Cell Host Microbe 21:156-168. 